\title{
Saussure, Bréal e a questão do sentido
}

Dayanne Teixeira Lima ${ }^{1}$

\section{Resumo}

Sabe-se que Ferdinand de Saussure foi contemporâneo de Michel Bréal. No entanto, um fato minimamente curioso é o da ausência de uma discussão sobre as ideias de Bréal na teorização de Saussure. Partindo desse pressuposto, o presente trabalho, de natureza teórica, tem o objetivo de discutir alguns aspectos da reflexão desses autores acerca do sentido, com o intuito de problematizarmos o "silêncio" saussuriano em relação às ideias do mestre francês. Para abordarmos a teorização saussuriana, partiremos de sua obra póstuma, o Curso de Linguística Geral, de 1916, e dos manuscritos reunidos e publicados, em 2002, por Simon Bouquet e Rudolf Engler nos Escritos de Linguística Geral; já a perspectiva bréaliana será abordada a partir de seu Ensaio de Semântica, publicado em 1897. Parece-nos que o estatuto necessariamente sincrônico do signo, proposto por Saussure a partir da oposição sincronia/ diacronia, desautoriza a possibilidade de uma abordagem histórica do sentido, tal como propôs Bréal.

Palavras-chave: Saussure. Bréal. Sentido. Sincronia e Diacronia

\footnotetext{
${ }^{1}$ Doutoranda em Linguística pela Universidade Federal de Alagoas. Mestra em Linguística pela mesma instituição.
} 


\section{Introdução}

Ferdinand de Saussure e Michel Bréal são dois personagens de destaque na história da Linguística: sabe-se que, ao primeiro, é dado comumente o título de "pai da Linguística Moderna"; já ao segundo são atribuídos o pioneirismo no emprego do termo "semântica" e, também, o título de "fundador da Semântica". Mas, a nosso ver, reduzir a contribuição desses autores a uma mera informação histórica (como tem sido feito, muitas vezes, nos manuais introdutórios da área) ofusca a visão do contexto histórico de suas teorizações, sem o qual uma compreensão efetiva de suas ideias é impossibilitada. Para nos desviarmos de uma redução problemática desse tipo, é crucial, pois, retornarmos às ideias de Saussure e de Bréal, situando-as no cenário da época, a saber, o século XIX, e, a partir daí, refletirmos sobre os efeitos dessas ideias para a ciência linguística.

Atualmente, o retorno a Saussure tem sido uma constante. Inicialmente, esse retorno esteve associado, sobretudo, à discussão em torno da veracidade do Curso de Linguística Geral (doravante CLG), publicado em 1916, cuja autoria é dada a Saussure. É demasiadamente sabido que tal obra é resultado de uma "assimilação e reconstituição" do pensamento saussuriano realizadas por seus editores, Charles Bally e Albert Sechehaye, com a colaboração de Albert Riedlinger, a partir de anotações do próprio Saussure e de alguns dos alunos que estiveram presentes nos três cursos ministrados pelo linguista nos anos 1906-1907, 1908-1909 e 1910-1911, em Genebra.

Por ser uma obra "de segunda mão", conforme salienta Salum (2006 [1916]), em seu prefácio à edição brasileira do CLG, colocou-se em xeque a autenticidade do livro, ou seja, a fidelidade ou não dos editores em relação às ideias saussurianas lá veiculadas, questão esta acalorada pela publicação dos manuscritos de Saussure, dos anos 50 até mais recentemente, final dos anos 90, alguns deles reunidos e publicados nos Escritos de Linguística Geral (doravante ELG), em 2002, por Simon Bouquet e Rudolf Engler. Desde então, temos testemunhado diversos trabalhos de autores nacionais e internacionais que trazem Saussure à tona e que, necessariamente, se posicionam diante da "arena da polêmica" em torno do CLG ${ }^{2}$, para usarmos os termos de Fiorin et al. (2013, p. 17).

\footnotetext{
2 Os limites deste trabalho não nos permitem avançarmos na discussão sobre a polêmica em torno da veracidade do CLG. Assumiremos, com Normand (2009, 2011), a legitimidade da obra póstuma. Seguindo a perspectiva da autora, centraremos nossa atenção "naquilo que desempenhou um papel histórico na pesquisa Linguística, o Curso de 1916, durante muito tempo o único texto acessível aos linguistas em seu trabalho ordinário" (NORMAND, 2011, p. 13).
} 
Em contrapartida, não encontramos a mesma efervescência no que diz respeito às pesquisas sobre Bréal, sobretudo no contexto nacional, fato este atestado por Dall'CortivoLebler (2017), em seu trabalho intitulado Do sentido ao valor: relações teóricas entre a Semântica de Michel Bréal e o Estruturalismo de Ferdinand de Saussure. Segundo a autora, "no Brasil, raros são os trabalhos que têm como tema a obra de Bréal e mais rara ainda é a menção do estudioso nos cursos de Letras” (DALL'CORTIVO-LEBLER, 2017, p. 1966-1967).

Sem discutirmos, por ora, as possíveis razões para esse "desinteresse" pela discussão das ideias bréalinas, concordamos com o ponto de vista de Guimarães (1992), em seu prefácio à edição brasileira do Ensaio de Semântica, a principal obra de Bréal, publicada em 1897 e, portanto, anterior à versão canônica do Cours. Partindo do pressuposto de que o CLG estabelece, sob muitos aspectos, um "corte decisivo" na história da linguística, Guimarães (1992, p. 9) defende que estudar Bréal pode ser uma forma de "desautomatizar as leituras do Curso" e, como consequência, "contribuir para uma desautomatização do discurso da linguística e do discurso sobre Saussure”.

Um fato histórico justifica uma possível leitura do CLG apoiada no pensamento bréalino: Saussure foi contemporâneo de Bréal. Conforme já mencionado acima, ambos estão circunscritos no século XIX e, portanto, no mesmo espaço de discussão linguística da época. Foi Bréal, aliás, quem indicou Saussure para atuar como professor na École des Hautes Études, em 1881, e, também, para substituí-lo no Cóllege de France anos mais tarde, embora, por razões até então desconhecidas ${ }^{3}$, Saussure não tenha assumido o cargo neste último. A relação entre o linguista francês e o jovem linguista franco-suíço, bem como a admiração daquele por este são, pois, atestadas.

Tendo como base esse fato histórico, alguns trabalhos defendem uma aproximação teórica entre Saussure e Bréal, tais como os de Aarsleff (1981), intitulado Bréal, la Sémantique et Saussure, e, mais recentemente, o de Dall'Cortivo-Lebler (2017), já mencionado. Para esses autores, de um modo geral, Bréal pode ser visto como aquele que antecede algumas das ideias saussurianas que ressurgiriam, mais tarde, no próprio CLG, sobretudo aquelas que dizem respeito aos "princípios de linguística geral”, tais como as noções de língua, valor, sincronia, diacronia etc.

\footnotetext{
${ }^{3}$ Cogita-se a ideia de que Saussure talvez tivesse se recusado a requerer a nacionalidade francesa, algo indispensável para que ele pudesse substituir Bréal no Cóllege de France (ARRIVÉ, 2010, p. 38).
} 
Dall'Cortivo-Lebler faz, ainda, uma ressalva: embora alguns pesquisadores de Saussure e de Bréal não apontem indícios de que a convivência de ambos, na França, tenha sido decisiva para a aproximação teórica entre eles, ela considera fundamental

[...] o fato de ambos os estudiosos terem mantido contato, o que permitiu que Saussure conhecesse o trabalho do semanticista e que este, por sua vez, acompanhasse o desenvolvimento das ideias do jovem genebrino (DALL'CORTIVO-LEBLER, 2017, p. 1969-1970).

Porém, um fato minimamente curioso em nossa leitura do CLG pode ser observado: não há nenhuma menção a Bréal ou à sua obra. Já nos ELG, observamos dois momentos em que o nome do linguista francês é convocado por Saussure, mas, ainda assim, sem uma discussão aprofundada sobre sua semântica. São esses: em Antigos Item, especificamente na página 92, quando Saussure discute o termo elipse (noção também discutida por Bréal), e em Antigos Documentos, pontualmente na página 219, quando o mestre genebrino reflete sobre o tipo de entidade que a Linguística tem diante de si. Vale ressaltar, desde então, que, ao partirmos dos ELG, lidamos, neste trabalho, não com manuscritos saussurianos propriamente ditos, mas com a edição destes realizada por Engler, na edição de 1968-74, e publicada, posteriormente, por Bouquet e Engler em 2002.

Tendo como fato a curiosa ausência de Bréal no CLG e nos ELG, nos questionamos: qual a possível razão para o genebrino não ter discutido as ideias de Bréal, seu eminente mestre? Diante desse questionamento, este trabalho, de natureza teórica, tem o objetivo de discutir alguns aspectos da reflexão de Saussure e de Bréal acerca do sentido, com o intuito de problematizarmos o "silêncio" saussuriano em relação às ideias bréalianas. Para abordarmos o ponto de vista saussuriano, partiremos de seu Curso de Linguística Geral e dos Escritos de Linguística Geral; já a perspectiva bréaliana será abordada a partir de seu Ensaio de Semântica. No decorrer da discussão, serão convocados, também, trabalhos de autores que discutem as ideias dos dois mestres.

A fim de cumprirmos nosso propósito, dividiremos este trabalho em três partes: na primeira, situaremos Saussure e Bréal no contexto do século XIX para identificarmos, minimamente, as escolas linguísticas da época e o modo como os linguistas nelas se inscrevem; na segunda, abordaremos especificamente alguns dos aspectos relacionados à discussão sobre o sentido realizada por Saussure e por Bréal, com o objetivo de compreendermos como tais aspectos podem estar atrelados ao silêncio saussuriano em 
relação à semântica bréaliana; e, por fim, teceremos nossas considerações finais acerca da temática aqui contemplada.

\section{Saussure e Bréal: linguistas do século XIX}

Gostaríamos de insistir, primeiramente, num aspecto fundamental da formação de Saussure e de Bréal que conduz esta seção: ambos são linguistas do século XIX. Isso significa dizer que, embora os efeitos de suas obras (sobretudo a de Saussure) possam ser sentidos, mais fervorosamente, a partir do século XX em diante, suas formulações dialogam, cada uma à sua maneira, com as abordagens linguísticas do período oitocentista, e, por isso, julgamos pertinente situarmos os dois autores nesse contexto.

No entanto, discutir as características que marcam o século XIX no que diz respeito aos estudos sobre a linguagem seria uma tarefa impraticável nos limites deste trabalho. Ao invés disso, destacaremos, brevemente, as principais pautas linguísticas sobre as quais Saussure e Bréal se posicionaram, assim como alguns dos desdobramentos teóricos que derivam desses posicionamentos.

Boa parte dos trabalhos desenvolvidos no século XIX é orientada pela escola denominada Gramática Comparada. O marco histórico dessa corrente é, notadamente, a publicação, em 1816, do livro do linguista alemão Franz Bopp, intitulado Uber das conjugationssystem der Sanskritsprache in Vergleichung mit jenem der griechischen, lateinischen, persischen und germanischen sprache. Segundo Morpurgo Davies (1998, p. 129), "this is the book that has been celebrated again and again as the first comparative work about the Indo-European languages". Além disso, a autora destaca que "[...] with Bopp, more than with A. W. Schlegel, the institutionalization (and the specialization) of linguistics begins" (MORPURGO DAVIES, 1998, p. 130) ${ }^{4}$.

Robins (1983) salienta que o mérito da Gramática Comparada não está no desenvolvimento de estudos históricos das línguas, pois estes já aconteciam no século passado (como, por exemplo, o trabalho do italiano Dante, De vulgari eloquentia, que já considerava o aparecimento de diferentes línguas ligadas a uma fonte comum), ainda que

\footnotetext{
${ }^{4}$ Remetemos o leitor ao trabalho de Morpurgo Davies (1998), intitulado History of linguistics: nineteenth century linguistics, no qual a autora apresenta um panorama, rico em detalhes, da linguística produzida no século XIX, fundamental para compreendermos as discussões típicas dessa época.
} 
esporadicamente. Segundo ele, a novidade está no fato de que o século XIX "assistiu ao desenvolvimento de modernos conceitos, teóricos e metodológicos, no terreno históricocomparativo e à concentração neste domínio linguístico da maior parte dos esforços e talento dos linguistas" (ROBINS, 1983, p. 132).

Saussure e Bréal, embora apresentem críticas à escola comparatista, como veremos adiante, estão inseridos nessa corrente linguística, de modo que podem ser considerados, também, autores fundamentais para a consolidação dessa abordagem no século XIX.

Normand (2009, p. 177) afirma que Bréal foi mestre de toda a geração dos primeiros linguistas comparatistas e que "sua tradução da Gramática Comparada, de Bopp (em 1866), permitiu o desenvolvimento do comparatismo na França". Segundo Guimarães (1992, p. 221), o linguista francês entrou, em 1864, para o Collège de France no ensino de gramática comparada e, em 1868, participou do grupo que fundou a École des Hautes Études, da qual foi diretor e, também, professor de alunos "ilustres", como o próprio Saussure. Nessa direção, Bréal, sem dúvida, foi uma figura importante para o desenvolvimento da Gramática Comparada no contexto francês.

Saussure, por sua vez, foi, de início, mais conhecido "[...] pelo importante trabalho que realizou no âmbito da linguística comparativa indo-europeia" (ROBINS, 1983, p. 162). O Mémoires sur le Système Primitif des Voyelles dans les Langues Indo-Européens, publicado em Leipzig, em 1879, é um trabalho que expressa bem a formação e a competência do genebrino enquanto um linguista comparatista, apesar de já haver, nesse trabalho, noções de sistematicidade que seriam aprofundadas, mais tarde, no CLG, com destaque para a noção de valor linguístico. Tal obra foi, ainda, segundo Arrivé (2010, p. 36), bem acolhida por alguns linguistas da época, especialmente na França.

Contudo, no final do século XIX, o cenário linguístico europeu começa a se modificar graças ao surgimento do movimento neogramático. Tal movimento se opôs radicalmente à concepção naturalista de língua disseminada pelos comparatistas e, como nos recorda Dall'Cortivo-Lebler (2017, p. 1970), Bréal e Saussure se situam, também, nessa virada linguístico-científica.

Diversas são as passagens nos textos de Bréal e de Saussure que expressam verbalmente a oposição desses autores ao naturalismo que caracterizou parte da doutrina comparatista. Em seu Ensaio de Semântica, já na introdução, Bréal tece duras críticas a 
August Schleicher, um dos maiores expoentes da Gramática Comparada, como podemos observar no trecho abaixo:

Poucos livros, num escasso volume, contêm tantos paradoxos quanto o pequeno livro em que Schleicher dá suas ideias sobre a origem e o desenvolvimento das línguas. Esse espírito, habitualmente tão claro e tão metódico, esse botânico, esse darwiniano, revela aí hábitos de pensamento que se esperariam, sobretudo, em algum discípulo da escola mística (BRÉAL, $1992[1897]^{5}$, p. 18).

Em A linguística é uma ciência naturale, Bréal (1992 [1897], p. 195), ao compreender que "tudo, na linguagem, vem do homem e se endereça ao homem", defende a necessidade de "colocar a ciência da linguagem entre as ciências históricas". Mais adiante, ele menciona alguns dos linguistas representantes da Gramática Comparada, tais como o próprio Schleicher, Max Müller e Arsène Darmesteter, e avalia o que há de semelhante em suas definições de língua, aspecto do qual ele se afasta radicalmente: “o que há de comum dessas diferentes definições é atribuir à linguagem uma existência própria, independentemente da vontade humana. Faz dela uma espécie de quarto reino” (BRÉAL, 1992 [1897], p. 195).

No capítulo I da Introdução do CLG, Saussure faz uma retomada da história da linguística, da qual a Gramática Comparada faz parte, e aponta o que entende como um dos equívocos cometidos por essa escola, a saber, o fato de esta ter sido "exclusivamente comparativa, em vez de histórica". Mais adiante, o genebrino acrescenta:

Esse método exclusivamente comparativo acarreta todo um conjunto de conceitos errados, que não correspondem a nada na realidade e que são estranhos às verdadeiras condiçôes de toda linguagem. Considerava-se a língua como uma esfera à parte, um quarto reino da Natureza; daí certos modos de raciocinar que teriam causado espanto em outra ciência (SAUSSURE, 2006 [1916], p. 10, grifo nosso).

Em Antigos Documentos (Edição Engler 1968-1974), já mencionado na introdução deste trabalho, especificamente no texto correspondente à primeira conferência de Saussure na Universidade de Genebra, datada de 1891, o mestre assim se dirige a seus interlocutores:

[...] houve, Senhores, como sabem, um tempo em que a ciência da linguagem tinha convencido a si mesma de que era uma ciência natural, quase uma ciência física; eu não pretendo demonstrar como isso era uma profunda ilusão de sua parte mas, ao contrário, constatar que esse debate está encerrado e bem encerrado. À medida que se compreende melhor a

\footnotetext{
${ }^{5}$ Optamos por informar, ao lado da data de publicação da obra consultada e entre colchetes, a data de publicação da versão original.
} 
verdadeira natureza dos atos de linguagem, tão próximos a nós mas, na mesma medida, tão difíceis de captar em sua essência, tornou-se mais evidente que a ciência da linguagem é uma ciência histórica e nada além de uma ciência histórica (SAUSSURE, 2004 [2002], p. 130, grifo nosso).

Já em Novos Documentos (Acervo BPU 1996), Saussure avalia como uma "conquista dos últimos anos" o fato de ter-se colocado "[...] a linguagem e a língua em seu verdadeiro nicho exclusivamente no sujeito falante seja como ser bumano seja como ser social' (SAUSSURE, 2004 [2002], p. 116, grifo nosso). Ou seja, a linguagem/língua, para Saussure, não está situada na natureza, como um "ser vivo independente", mas, necessariamente, no sujeito falante, tanto do ponto de vista da espécie humana quanto do ponto de vista do indivíduo social.

De tudo o que foi discutido até aqui, pudemos constatar que tanto Bréal quanto Saussure estiveram engajados em atividades acadêmicas (aulas, publicações, etc.) vinculadas às pautas linguístico-científicas do século XIX. Eles acompanharam, também, a passagem (não imediata) de uma doutrina comparatista para uma doutrina neogramática, se opondo à ideia de língua enquanto um organismo vivo e reivindicando o lugar da linguística nas ciências históricas.

Porém, uma observação importante feita por Dall'Cortivo-Lebler, mais especificamente em relação a Bréal, e que cabe, aqui, destacarmos, é a de que, apesar de o linguista francês se contrapor fortemente aos postulados comparatistas, "[...] não é possível afirmar que Bréal não tenha sofrido qualquer influência dessa escola" (DALL'CORTIVOLEBLER, 2017, p. 1973). Acrescentamos, nessa direção, que a própria ideia de lei na noção bréaliana de leis intelectuais da linguagem, embora esteja relacionada à construção e alteração do sentido, pode ser entendida como um efeito da noção de leis fonéticas, tão discutida e disseminada pelos estudos comparatistas.

Milner (2012), por sua vez, entende que não há uma ruptura entre Saussure e a Gramática Comparada. Nessa direção, assume que Saussure não é o fundador da ciência linguística, mas um continuador da ciência linguística inaugurada por Bopp: Segundo ele, para o mestre genebrino, “[...] a linguística existe - é a gramática comparada -, o problema é que ela ignora aquilo que a possibilita" (MILNER, 2012, p. 51).

Não cabe, aqui, discutirmos pormenorizadamente as colocações de Dall'CortivoLebler e Milner acerca do vínculo entre Bréal e Saussure, respectivamente, e a Gramática Comparada, mas é pertinente apontá-las com o intuito de nos desvincularmos de uma noção de ruptura radical entre os dois teóricos e tal escola, tal como é, muitas vezes, 
aludida em alguns manuais de linguística. Além disso, partir do pressuposto de que há, em certa medida, uma continuidade entre esses autores e a Gramática Comparada nos leva a considerar o modo como eles "conciliam" as descobertas teórico-metodológicas dos estudos histórico-comparatistas com a virada linguístico-científica do final do século.

Para finalizarmos, gostaríamos de destacar um desdobramento importante da postura de Bréal e de Saussure ao assumirem a linguística enquanto uma ciência histórica: o reestabelecimento do lugar do sujeito falante na língua. Pontuamos, desde já, que as consequências teóricas oriundas desse reestabelecimento não são as mesmas para ambos os autores, sobretudo quando se está em questão a possibilidade de reconstrução do sentido. É o que discutiremos a seguir.

\title{
A questão do sentido nas perspectivas bréaliana e saussuriana: o distanciamento
}

Para começar, destacamos um trecho do trabalho de Aarsleff (1981). Nele, o autor ressalta a relevância da obra de Bréal para a linguística francesa, questionando até mesmo o lugar de originalidade dado comumente a Saussure:

\begin{abstract}
Bref, il faut rendre à Bréal sa place de grand innovateur, qui conféra à la linguistique française la forme distincte et puissante qui impressionnera le monde savant, par une sorte d'action à retardement, à travers ce qui en constitue la somme: le Cours. Que cela rende Saussure un peu moins original qu'on ne l'écrit d'ordinaire, voilà qui dépend de l'appréciation de chacun. Bien sûr, sa pensée montre (notamment dans la terminologie) une autre qualité systématique, dont on connait la fécondité. Reste que Bréal fournit la base intellectuelle, il faut s'en souvenir, qui conféra à la nouvelle linguistique sa fraîcheur - toute française - de caractère et de principes (AARSLEFF, 1981, p. 127).
\end{abstract}

Dall'Cortivo-Lebler (2017), por sua vez, faz um balanço sobre os resultados de seu trabalho e coloca Bréal numa posição de quem, para além de fundador da Semântica, discutiu questões relacionadas à linguística geral, razão pela qual entende que há um "paralelo" entre o linguista francês e Saussure:

Nosso objetivo neste trabalho foi traçar um paralelo entre determinados conceitos e ideias desenvolvidos por Bréal e por Saussure. Vimos que Bréal, muito mais que ser o fundador da ciência das significações, delineou aspectos importantes relativamente à concepção de qual seria o objeto de estudo das ciências linguísticas, bem como a natureza deste objeto (DALL'CORTIVO-LEBLER, 2017, p. 1986). 
Observamos, nesses autores, a tônica da questão: para eles, Bréal, tanto quanto Saussure (ou até antes mesmo de Saussure), apresenta uma reflexão acerca dos aspectos gerais da linguagem. A ideia é a de que tais aspectos da reflexão bréaliana "ressurgem" no CLG, alguns deles com a mesma terminologia, tais como as noções de lingua, fala e valor, e outros que

não chegaram a ser cunhados terminologicamente por Bréal, mas se assemelhariam às definições de sincronia, de diacronia, de sintagma, de estrutura, dentre outros aspectos, como o arbitrário do signo e a língua como algo socialmente dado e como fruto da coletividade (DALL'CORTIVO-LEBLER, 2017, p. 1972).

É por essa razão que Aarsleff e, mais recentemente, Dall'Cortivo-Lebler entendem que é pertinente conceber uma aproximação teórica entre os mestres francês e genebrino, ou seja, que os pensamentos de Bréal e de Saussure, embora distintos, seguem um percurso semelhante: o de discutir noções relativas à linguística geral. No entanto, para nós, muito além do que identificar uma possível comunhão de ideias entre Bréal e Saussure, é preciso compreender qual o direcionamento tomado por eles quando da articulação dos conceitos de língua, de fala, de sincronia e de diacronia, por exemplo, com suas respectivas teorizações. Seria esse direcionamento o mesmo para ambos?

Contrariamente a Aarsleff e Dall'Cortivo-Lebler e a partir do fato do "silêncio" de Saussure para com a teorização de Bréal, discutiremos um aspecto que, a nosso ver, coloca o mestre genebrino numa direção diametralmente oposta à do mestre francês: a discussão acerca da reconstrução do sentido. Como já mencionado acima, tal divergência é reflexo, em parte, do modo como cada um concebe o sujeito falante na língua. Abordaremos, a seguir, as colocações de Bréal e, na sequência, partiremos para as de Saussure.

Segundo Guimarães (1992), Bréal está circunscrito no historicismo de sua época, ou seja, na percepção de que "o histórico é essa direção do progresso". Porém, adverte-nos sobre a necessidade de especificar melhor a postura do autor "para que não a confundamos com outras, as mecanicistas, naturalistas, do século XIX” (GUIMARÃES, 1992, p. 9). Segundo o autor, um dos fatores que distancia Bréal da perspectiva naturalista é que o linguista situa a linguagem no homem e para o homem; acresce a isso o fato de que, para o mestre francês, a linguagem é um instrumento de civilização:

A linguística fala ao homem dele mesmo: ela lhe mostra como ele construiu, como aperfeiçoou, por sobre obstáculos de toda natureza, 
malgrado inevitáveis demoras, e mesmo recuos momentâneos, o mais necessário instrumento de civilização (BRÉAL, 1992 [1897], p. 17, grifo nosso).

Guimarães, então, explica que "o histórico [em Bréal] diz respeito à intervenção do sujeito na linguagem, da vontade na linguagem, que é inclusive uma intervenção da vontade na inteligência” (GUIMARÃES, 1992, p. 11, grifo nosso). Essa intervenção do sujeito, ou seja, a vontade bumana é, para Bréal, a "causa verdadeira" do desenvolvimento da linguagem (BRÉAL, 1992 [1897], p. 19).

Ainda segundo Guimarães (1992, p. 10), a concepção bréaliana de vontade "não é nem vontade consciente nem fenômeno instintivo". Uma definição do termo pode ser encontrada já na introdução do Ensaio, quando Bréal reivindica o lugar da vontade na história da linguagem. Nas palavras do autor:

Fazer intervir a vontade na história da linguagem, isso parece quase uma heresia, já que, durante cinquenta anos, tantos cuidados se tomou para bani-la [...] É preciso fechar os olhos à evidência para não ver que uma vontade obscura, mas perseverante preside às mudanças da linguagem (BRÉAL, 1992 [1897], p. 19, grifo nosso).

Outro aspecto importante em relação à concepção bréaliana de vontade na linguagem: ela não se restringe a de apenas um indivíduo, mas corresponde a "muitas vontades". Nas palavras de Bréal: "ela [a linguagem] é feita pelo consentimento de muitas inteligências, de acordo com muitas vontades, umas presentes e atuantes, outras depois de muito tempo desfeitas e desaparecidas” (BRÉAL, 1992 [1897], p. 197). Nessa direção, Dall'Cortivo-Lebler (2017, p. 1977, grifo nosso) enfatiza que, para o linguista francês, "[...] a mudança é um empreendimento coletivo e não fruto da ação de leis estranhas aos falantes". É a coletividade, pois, que legitima a mudança linguística.

Quando Bréal discute mudança linguística, ele se refere a que tipo de mudança? Certamente, não se trata da mudança dos sons (formas), amplamente abordada pela abordagem naturalista, mas a dos sentidos. O próprio termo semântica, que dá nome à "ciência das significações" proposta pelo autor, se constitui em oposição à fonética, a "ciência dos sons" (BRÉAL, 1992 [1897], p. 20). Um dos motivos apresentados pelo linguista para justificar seu interesse pelo estudo dos sentidos é o de que a história das formas “[...] n'est que la moitié de la grammaire comparative et que cette étude purement extérieure des mots doit toujours être éclairée et contrôlée par l'examen de la signification" (BRÉAL apud AARSLEFF, 1981, p. 119). 
A história que interessa a Bréal é, pois, a dos sentidos. Segundo Dall'CortivoDebler (2017, p. 1981) ao tratar de semântica, Bréal discute diversos processos pelo quais “os sentidos, na língua, são modificados, incorporados, multiplicados ou desfeitos. O linguista pondera que todas as mudanças envolvendo o aspecto semântico das palavras são resultado do trabalho do "povo"'.

A respeito da relação entre as mudanças de sentido e o "povo", no ensaio intitulado A história das palavras ${ }^{6}$, Bréal afirma:

Normalmente as mudanças de sentido das palavras são obra do povo, e como em todo lugar onde a inteligência popular está em jogo, é preciso confiar, não numa grande profundidade de reflexão, mas em intuições, em associações de ideias, às vezes imprevistas e bizarras, mas sempre fáceis de acompanhar. É, pois, a um espetáculo curioso e atraente que nos convida essa bistória (BRÉAL, 1992 [1897], p. 181, grifo nosso).

Sendo as mudanças de sentido obra do povo, Bréal (1992 [1897], p. 19) se propõe a estudar "as causas intelectuais que presidiram as transformações de nossas línguas", e o faz "seguindo um certo número de leis". No entanto, tais leis, segundo ele, não devem ser tomadas no sentido "imperativo", nem são tampouco "leis sem exceção, leis cegas, como são, se é necessário acreditar em alguns de nossos confrades, as leis da fonética". Isso porque a própria assunção de "leis fonéticas cegas", na Gramática Comparada, independe da vontade do sujeito e de uma relação com o sentido, o que não condiz com a proposta de Bréal. Toda a primeira parte do Ensaio é destinada ao que o mestre francês chama de "leis intelectuais da linguagem".

Em razão dos limites deste trabalho, não nos aprofundaremos na discussão bréaliana acerca das leis intelectuais responsáveis pelas mudanças dos sentidos na história das línguas. No entanto, gostaríamos de destacar, a esse respeito, o fato de que a centralidade do estudo semântico de Bréal está na relação do homem (leia-se da vontade bumana) com a língua e nas leis intelectuais que daí emanam. Como ele mesmo irá afirmar em A história das palavras: "fora de nosso espírito, a linguagem não tem vida nem realidade" (BRÉAL, 1992 [1897], p. 181).

Nessa perspectiva, o estudo diacrônico da língua proposto por Bréal se propõe a "contar" a história dos significados (e não dos sons) que, necessariamente, acompanham a

\footnotetext{
${ }^{6}$ De acordo com Aarsleff (1981, p. 117), os ensaios A bistória das palavras (1887) e Lingua e nacionalidade (1891) de Bréal "[...] offrent l"exposé le plus pénétrant et le plus condensé de sa sémantique”. Ambos foram incluídos no Ensaio de Semântica.
} 
trajetória de um povo, que se entrelaçam às atividades sociais de uma "coletividade diversa":

À medida que uma civilização avança em diversidade e riqueza, as ocupações, os atos, os interesses que compõem a vida em sociedade se distribuem entre diferentes grupos humanos: nem o estado de espírito, nem a direção da atividade são os mesmos para o padre, o soldado, o político, o artista, o comerciante, o agricultor. Embora tenham herdado a mesma lingua, as palavras assumem para cada um deles nuanças distintas, que se fixam e terminam por aderir a elas. $O$ hábito, o meio, toda a atmosfera ambiental determinam o sentido da palavra e corrigem o que ela tinha de generalidade excessiva (BRÉAL, 1992 [1897], p. 184, grifos nossos).

Em contraste, ainda, com o estudo das formas, o estudo da história dos sentidos, segundo Bréal, exige um "conhecimento íntimo e direto" do linguista para com a língua em questão. Isso porque

as modificações sobrevindas no corpo da linguagem, tais como a supressão de uma letra ou de uma sílaba, o acréscimo de uma nova reflexão, a substituição de uma desinência por outra, saltam aos olhos à primeira vista, mas as observações das quais se ocupa o semanticista se ocultam um pouco mais ao olhar (BRÉAL, 1992 [1897], p. 182).

Cumpre destacar, nessa direção, que a grande maioria dos exemplos utilizados por Bréal em seu Ensaio são oriundos de sua língua materna, a língua francesa.

Por fim, antes de nos dirigirmos para a teorização saussuriana, retomemos o que Bréal nos diz sobre a percepção do sujeito falante para com o deslocamento dos sentidos na história da língua.

Ao mencionar a obra de Dumarsais, gramático do século XVIII, o linguista francês explica que esse trabalho tentou "tornar visível aos olhos" o surgimento dos diferentes sentidos de uma palavra. E pondera: "mas é preciso lembrar-se de que essas figuras complicadas só têm valor para o linguista [...] O povo não tem por que remontar ao passado: ele só conbece a significação do momento" (BRÉAL, 1992 [1897], p. 187, grifo nosso). Ou seja, para Bréal, o sujeito falante desconhece o passado de sua língua, e, do ponto de vista das significações, o que importa para esse sujeito é o sentido presente. No entanto, o autor insiste na reconstrução dos sentidos pelo linguista, em função mesmo da centralidade que o sujeito falante assume em sua teorização.

Quando Bréal discute, por exemplo, a restrição do sentido, aspecto, segundo ele, de "real importância" para a história dos sentidos, o que impera é a ação do "espírito" sobre a 
linguagem: ao refletir sobre o caso do verbo traire, da antiga língua francesa, o autor questiona o que faz com que esse verbo tenha se reduzido à única significação de traire les vaches, trair ele lait. E, em seguida, responde: É que uma rival de origem germânica - tirerinvadiu e ocupou, no curso dos séculos, todo seu domínio. Nosso espirito se recusa a guardar riquezas inúteis: ele descarta ponco a ponco o supérfluo (BRÉAL, 1992 [1897], p. 182, grifo nosso).

Mais adiante, Bréal defende, contra toda a ideia de leis matemáticas precisas, tais como as que eram concebidas pela fonética, que é "o cérebro, da mesma forma que a laringe, que é a causa das mudanças". E complementa afirmando ser necessário distinguir "[...] os fenômenos que dizem respeito à estrutura dos órgãos e a uma imperiosa necessidade de pronúncia, e aqueles que vêm do instinto de imitação e de simples preferências" (BRÉAL, 1992 [1897], p. 194). De modo geral, para Bréal, a reconstrução histórica dos sentidos reclama pelo sujeito falante, mais especificamente, pelo estudo das leis intelectuais que explicam essa história. Passemos, agora, para a reflexão saussuriana acerca do sentido.

De início, mencionamos uma nota de rodapé do CLG na qual os editores fazem uma advertência: segundo ele, "deve-se cuidar de não confundir a Semiologia com a Semântica, que estuda as alterações de significado e da qual F. de S. não fez uma exposição metódic" (SAUSSURE, 2006 [1916], p. 24). E, em seguida, remetem o leitor ao capítulo Imutabilidade e mutabilidade do signo, mais especificamente ao tópico sobre a mutabilidade, no qual, segundo eles, pode ser encontrada a formulação do "princípio fundamental".

Vê-se, na referida nota, a acepção do termo semântica enquanto ciência das "alterações de significado" e a declaração de que tal assunto não fazia parte das principais pautas saussurianas, o que pode justificar, em parte, o "silêncio" de Saussure em relação à ciência inaugurada por Bréal.

Para abordarmos o sentido na discussão saussuriana é preciso, inicialmente, situá-lo na concepção de signo linguístico proposta pelo genebrino. O signo, para ele, "une não uma coisa e uma palavra, mas um conceito e uma imagem acústica” (SAUSSURE, 2006 [1916], p. 80). Logo, o sentido sobre o qual Saussure se debruça se afasta radicalmente do apelo à

\footnotetext{
${ }^{7}$ Aqui, vale destacar que Arrivé (2010, p. 36-37) menciona, com apreço, a tese de doutorado de Saussure em filosofia, intitulada De l'emploi du génifit absolu em sanskrit, que, segundo ele, "[...] dá testemunho do precocíssimo interesse de Saussure pela sintaxe em suas relações com a semântica”.
} 
referência: é sentido que emana da língua, puramente das relações intralinguísticas entre os signos.

É demasiadamente sabido que Saussure concebe a língua enquanto um sistema de signos. Normand chama a atenção para o fato de que "a definição pelo sistema de signos, antes mesmo de ser esclarecido como é necessário entender esse tão velho termo signo, é assim estreitamente ligada à célebre demarcação sincronia/ diacronia" (NORMAND, 2009, p. 53, grifo da autora).

Ao abordar a trajetória da formulação dos conceitos de sincronia e diacronia por Saussure, Depecker (2012) aponta a relevância da distinção entre os dois:

Distinção tão importante que Saussure vincula 'estado de lingua' e 'transformação no tempo' a duas atividades que o conduziram a se questionar sobre a importância do tempo no estudo das línguas: a morfologia e a fonética. A morfologia trata prioritariamente das formas e, acrescenta Saussure, de seu 'valor'; a fonética trata da evolução dos 'sons' (DEPECKER, 2012, p. 52, grifos do autor).

Ou seja, para Saussure, a fonética está para a diacronia, assim como a morfologia está para a sincronia. Mais adiante, Depecker esclarece o que são os pontos de vista fonético e morfológico para o genebrino: [...] é preciso pelo menos fazer a distinção entre a abordagem fonética que, para Saussure, considera essencialmente o aspecto material da língua, e abordagem morfológica, que coloca em cena o "sujeito falante" (DEPECKER, 2012, p. 150).

Vimos anteriormente que, para o mestre genebrino, o verdadeiro nicho da língua está no sujeito falante. Dito de outra maneira, "a sincronia conhece somente uma perspectiva, a das pessoas que falam" (SAUSSURE, 2006 [1916], p. 106). A diacronia, por sua vez, é definida a partir do ponto de vista do conhecedor ; ela representa uma fase de evolução da língua, na qual as mudanças se aplicam apenas a elementos isolados (os sons ou formas), e não ao sistema como um todo.

Nessa perspectiva, do ponto de vista sincrônico, a unidade linguística percebida pelo sujeito falante é sempre o signo. A "massa falante" percebe não o significante isolado, mas sempre o significante que reclama um significado: "[...] se chamamos arbor signo, é somente

\footnotetext{
${ }^{8} \mathrm{O}$ conbecedor é o linguista, o estudioso, aquele que possui um saber sobre a língua, diferentemente do locutor, que apresenta um saber da lingua (NORMAND, 2009, p. 45).
} 
porque exprime o conceito 'árvore', de tal maneira que a ideia da parte sensorial implica a do total", insiste Saussure (2006 [1916], p. 81).

Em contrapartida, quando o linguista (e não o sujeito falante) se situa no ponto de vista diacrônico, segundo Saussure, "[...] não é mais a língua o que percebe, mas uma série de acontecimentos que a modificam" (2006 [1916], p. 106). Na diacronia, entram em jogo não as relações entre signos num sistema, mas as substituições de termos isolados que se sucedem no tempo.

Ao discutir o conceito de fonema em Saussure e seus desdobramentos, Faria (2018, p. 34) assume ser o significante linguístico "[...] a unidade da diacronia por ser a parte do signo que se propaga através do tempo e, portanto, deixa-se escrever através de raciocínios fonéticos". Para a autora, isso se explica em função de uma "segunda existência do signo" aludida por Saussure, que “[...] só se mantém quando se isola o signo de sua significação e de qualquer significação que lhe sobrevenha” (2004 [2002], p. 52).

Nessa perspectiva, a diacronia lida apenas com o significante, e não com o signo em sua totalidade, nem tampouco com o significado. Ou, para sermos mais enfáticos, em Saussure, o signo (e, com ele, o significado) é uma unidade necessariamente sincrônica, e, nesses termos, uma abordagem histórica dos sentidos, tal como propõe Bréal, torna-se uma atividade inconcebível, uma vez que a diacronia lida apenas com a parte "mais material" do signo.

Há diversas passagens (tanto no CLG quanto no ELG) que demonstram o fato de que, para Saussure, a significação compete necessariamente à sincronia, cabendo à diacronia apenas o aspecto material do signo. Nos Escritos, o mestre genebrino afirma:

O fato de que não há nada instantâneo que não seja morfológico (ou significativo), e que também não há nada morfológico que não seja instantâneo, é inesgotável nos desdobramentos que comporta. Mas esse primeiro fato tem, por contrapartida imediata, que nada há de sucessivo que não seja fonético (ou fora da significação), e que nada bá de fonético que não seja sucessivo (SAUSSURE, 2004 [2002], p. 41, grifo nosso).

E, em seguida, ele acrescenta:

[...] a significação é apenas uma maneira de exprimir o valor de uma forma, valor que depende completamente das formas coexistentes a cada momento, e que é, por conseguinte, uma empreitada quimérica, não apenas querer examinar essa significação em si mesma (o que não é nada linguístico), mas querer examiná-la com relação a uma forma, visto que 
essa forma muda e, com ela, todas as outras e, com estas, todas as significações, de maneira que só se pode dominar a mudança de significação vagamente com relação ao conjunto (SAUSSURE, 2004 [2002], p. 41, grifo nosso).

Situar a significação no domínio da sincronia não significa dizer que, para Saussure, os sentidos são imutáveis. A questão que deve ser colocada é como, na perspectiva saussuriana, a mudança linguística acontece. Nessa direção, o capítulo que versa sobre a imutabilidade e mutabilidade do signo, mencionado acima, é esclarecedor.

Cumpre salientar, primeiramente, que a mudança, para Saussure, é sempre o resultado de um deslocamento na relação entre o significante e o significado: "uma língua é radicalmente incapaz de se defender dos fatores que deslocam, minuto a minuto, a relação entre o significado e o significante" (SAUSSURE, 2006 [1916], p. 90), enfatiza o mestre. Essa é, segundo ele, uma das consequências da arbitrariedade do signo.

Porém, embora a arbitrariedade seja uma condição que permite à língua esse constante devir (princípio da mutabilidade), a fidelidade ao passado está sempre presente (princípio da imutabilidade): "a todo instante, a solidariedade com o passado põe em xeque a liberdade de escolher. Dizemos homem e cachorro porque antes de nós se disse homem e cachorro" (SAUSSURE, 2006 [1916], p. 88). Imutabilidade e mutabilidade são, pois, princípios complementares que explicam a vida das línguas: tradição e mudança. Continuidade e alteração. Resta, ainda, sabermos como se dá a alteração, fator que, a nosso ver, também distancia Saussure de Bréal.

Segundo Saussure, “o signo está em condições de alterar-se porque se continua. $O$ que domina, em toda alteração, é a persistência da matéria velha; a infidelidade ao passado é apenas relativa" (SAUSSURE, 2006 [1916], p. 89, grifo nosso). Seria a matéria velha aludida por Saussure o significante, a parte mais material do signo, que perpassa o tempo e se atualiza num estado sincrônico de língua? No capítulo sobre a linguística estática e a linguística evolutiva, o termo "matéria" reaparece, desta vez atrelada à noção de estado: "em cada estado, o espírito se insufla numa matéria dada e a vivifica" (SAUSSURE, 2006 [1916], p. 101, grifo nosso).

Parece-nos que o termo "matéria", além de remeter à ideia de tradição na língua, diz respeito à noção de significante, ou, mais especificamente, ao resíduo material do significante, passível de ser recuperado historicamente. Se o signo (e, com ele, a significação) está na língua e só pode ser percebido na perspectiva do sujeito falante, parece que, nesses 
termos, o sentido não pode ocupar o lugar de matéria velha que se transmite no tempo. De todo modo, Saussure é enfático ao afirmar que "é na fala que se acha o germe de todas as modificações" e, ainda, que "tudo quanto seja diacrônico na língua não o é senão pela fala" (SAUSSURE, 2006 [1916], p. 115, grifo do autor), e, nessa direção, parece pertinente insistir na qualidade material da unidade da diacronia.

Ainda a respeito da reflexão saussuriana, cumpre destacarmos que, para Saussure, diferentemente de Bréal, que propõe leis intelectuais para explicar as mudanças de sentido, as causas de alteração das línguas não são previsíveis. A única causa "palpável” se resume à "lei universal" do tempo. Nas palavras do autor:

As causas da continuidade estão a priori ao alcance do observador; não ocorre o mesmo com as causas da alteração através do tempo. Melhor renunciar, provisoriamente, a dar conta exata delas, e limitar-se a falar, em geral, do deslocamento das relações; o tempo altera todas as coisas; não existe razão para que a lingua escape a essa lei universal (SAUSSURE, 2006, [1916], grifo nosso).

Em outro momento, Saussure acrescenta: “[...] um fato diacrônico é um acontecimento que tem sua razão de ser em si mesmo; as consequências sincrônicas particulares que dele podem derivar são-lhe totalmente estranhas" (2006 [1916], p. 100).

Parece, pois, não haver espaço, na teorização saussuriana, para a vontade bumana ou para leis intelectuais da linguagem que expliquem as alterações de sentido no decorrer da história. Ou, ainda, para a possibilidade de reconstrução dos sentidos, haja vista que esses estão sempre situados no tempo presente. A mudança, para Saussure, é sempre resultante de um acidente de fala, cujas consequências sincrônicas não podem ser previstas. Para ele, é o aspecto material do signo (a matéria velha?) que entra em jogo em toda alteração, em toda a trajetória da língua no tempo, e que surte efeito em seu estado sincrônico, ou, mais especificamente, no sujeito falante.

\section{Considerações finais}

Iniciemos essas breves considerações finais destacando o que, para nós, parece ser uma resposta possível para o silêncio de Saussure em relação à semântica de Bréal: o estatuto sincrônico do signo proposto pelo mestre genebrino desautoriza uma abordagem 
diacrônica do sentido, haja vista que, desse ponto de vista, apenas a parte mais material do signo (o significante) é recuperável.

Até aqui, pudemos constatar que, embora Bréal e Saussure possam se aproximar em determinados aspectos que dizem respeito às demandas do final do século XIX, tais como o reestabelecimento do sujeito falante na língua e, como consequência disso, o rompimento com a ideia de organicismo natural em matéria de linguagem, os desdobramentos teórico-metodológicos de cada abordagem são distintos: enquanto, para Bréal, as leis intelectuais da linguagem, cerne de toda mudança linguística, permitem reconstruir o percurso dos sentidos no decorrer da história da língua, para Saussure, o sentido é, sempre, efeito do signo sobre o sujeito falante e, portanto, não pode ser concebido fora dessa realidade sincrônica.

Para Saussure, insistamos, o estatuto necessariamente sincrônico do signo linguístico, fruto da perspectiva do sujeito falante na língua, estabeleceu limites metodológicos imperiosos para o linguista: de um lado, vê-se a história da língua, "narrada" pela alteração da parte mais material do signo apenas; do outro, vê-se a língua, o funcionamento do sistema linguístico, que requer o signo em sua totalidade, sem o qual a significação é vaga. Em suma: ou faz-se diacronia dos sons, ou sincronia dos signos.

Por fim, gostaríamos de destacar a brevidade dessas considerações. Refletir acerca da teorização de Saussure e de Bréal, linguistas a quem são atribuídos os títulos de fundadores da linguística moderna e da ciência semântica, respectivamente, é um trabalho que exige inúmeras retomadas, sobretudo na atualidade, momento em que a Linguística passa por um movimento constante de retorno aos clássicos. Esperamos, com este trabalho, contribuir, em parte, para esse quadro, ou, ainda, para uma "desautomatização", tanto do pensamento de Saussure quanto do de Bréal. 


\section{Referências}

AARSLEFF, H. Bréal, la Sémantique et Saussure. Histoire, epistémologie, langage, v. 3, $\mathrm{n}^{\mathrm{o}} 2$, p. 115-134, 1981.

ARRIVÉ, M. Em busca de Ferdinand de Saussure. Trad. Marcos Marcionilo. São Paulo: Parábola Editorial, 2010.

BRÉAL, M. Ensaio de semântica. São Paulo: Pontes/Educ, 1992 [1897].

DALL'CORTIVO-LEBLER, C. Do sentido ao valor: relações teóricas entre a Semântica de Michel Bréal e o Estruturalismo de Ferdinand de Saussure. Revista de Estudos da Linguagem, Belo Horizonte, v. 25, nº 4, p. 1965-1987, 2017.

DEPECKER, L. Compreender Saussure a partir dos manuscritos. Trad. Maria Ferreira. Petrópolis: Editora Vozes, 2012.

FARIA, N. R. B. Entre a leitura da fala e a escrita da língua: o fonema em Saussure. DELTA. Documentação de Estudos em Linguística Teórica e Aplicada (Online), 2018 (no prelo).

FIORIN, J. L.; FLORES, V. do N.; BARBISAN, L. B. (Org.). Saussure: a invenção da linguística. São Paulo: Contexto, 2013.

GUIMARÃES, E. Prefácio “A linguística é uma ciência histórica?”. In: BRÉAL, M. Ensaio de semântica. São Paulo: Pontes/Educ, 1992 [1897].

MILNER, J-C. O amor da língua. Campinas: Editora da Unicamp, 2012.

MORPUGO DAVIES, A. History of linguistics: nineteenth century linguistics (v. IV). New York: Routledge, 1998.

NORMAND, C. Saussure. Trad. Ana de Alencar e Marcelo Diniz. São Paulo: Estação Liberdade, 2009.

Uma epistemologia da linguística. In: SILVEIRA, E. (Org.). As bordas da linguagem. Uberlândia: EDUFU, 2011.

ROBINS, R. H. Pequena história da linguística. Trad. Luiz M. Monteiro de Barros. Rio de Janeiro: Ao Livro Técnico, 1983.

SALUM, I. Prefácio. In: SAUSSURE, F. Curso de Linguística Geral. São Paulo: Cultrix, 2006 [1916].

SAUSSURE, F. de. Curso de Linguística Geral. São Paulo: Cultrix, 2006 [1916].

Escritos de Linguística Geral. Organizados e editados por Simon Bouquet e Rudolf Engler. São Paulo: Cultrix, 2004 [2002]. 


\begin{abstract}
It is known that Ferdinand de Saussure was a contemporary of Michel Bréal. However, a minimally curious fact is the absence of a discussion of Bréal's ideas in Saussure's theorizing. Based on this assumption, the present work, of a theoretical nature, has the objective of discussing some aspects of the reflection of these authors about the meaning, in order to problematize the saussurian "silence" in relation to the french master ideas. In order to approach Saussurian theorization, we will start with his posthumous work, the General Linguistics Course of 1916, and the manuscripts collected and published in 2002 by Simon Bouquet and Rudolf Engler in the Writings in General Linguistics; the bréalian perspective will be approached from his Semantic Essay, published in 1897. It seems to us that the necessarily synchronic status of the sign, proposed by Saussure from the synchrony/diacrony opposition, deters the possibility of a historical approach to meaning, as Bréal proposed.
\end{abstract}

Keywords: Saussure. Bréal. Meaning. Synchrony and Diacrony

Recebido em: 30/04/2018.

Aceito em: 14/06/2018. 